\title{
A REFORMA DAS NORMAS TRABALHISTAS EM MEIO À CRISE ECONÔMICA NO BRASIL
}

\author{
Roberta Laís Machado Martins Andrade 168 \\ Fernando Franco Morais ${ }^{169}$
}

Recebido em: 27/10/2017

Aprovado em: 20/11/2017

\begin{abstract}
RESUMO
O presente trabalho contempla uma análise da reforma dos direitos laborais, para fornecer subsídios à construção de soluções para a atual crise econômica vivenciada pelo Brasil. Neste sentido, possui como questionamento principal se alteração dos direitos trabalhistas atua para geração e manutenção de empregos. Possui como objetivos específicos: avaliar os benefícios e impactos que a manutenção de direitos laborais pode causar; definir crise; exemplificar os malefícios causados pela globalização ao trabalhador, abordar a questão do desemprego e a interferência do Estado no que se relaciona ao processo de flexibilização. O trabalho é bibliográfico, tendo como método adotado o dedutivo, baseado na consulta de fontes primárias e secundárias. Enfim, o trabalho busca alcançar respostas, para que a taxa de desemprego diminua, mostrando se a mudança nas normas jurídicas laborativas é ou não a solução para manutenção do trabalhador em seu posto de trabalho e uma saída para crise econômica.
\end{abstract}

Palavras-chave: Desemprego. Economia. Regulação jurídica do trabalho.

\section{INTRODUÇÃO}

O presente trabalho tem por finalidade permitir uma contextualização de um tema bastante discutido em meio a crise econômica: a reforma das leis trabalhistas brasileiras, com suas respectivas consequências, vantagens e desvantagens, levando em consideração os limites estabelecidos pela Constituição Federal de 1988.

\footnotetext{
168 Mestre em Direito com área de concentração em Empreendimentos Econômicos, Desenvolvimento e Mudança Social pela Universidade de Marília/UNIMAR. Pós-graduada em Direito do Trabalho pela Universidade Cândido Mendes. Advogada.

169 Mestre em Direito pela Universidade de Marília/UNIMAR. Pós-graduado pela Uniderp/LFG, UNIDERP/LFG. Advogado. Doutorado em andamento pela Universidad Nacional de Lomas de Zamora, UNLZ, Argentina.
} 
Este trabalho procura apresentar uma visão geral sobre o tema, embasado em doutrinas favoráveis e contrárias à tal mudança, com o objetivo geral de descobrir se em meio a crise econômica do Brasil, a flexibilização das normas trabalhistas seria a melhor solução para atenua-la. Como objetivos específicos, estão a definição de crise, os malefícios causados pela globalização, a questão do desemprego e uma síntese da interferência do Estado no que se relaciona à alteração da CLT.

Com o desígnio de conseguir o objetivo proposto, a pesquisa utilizará como método de abordagem o dedutivo, partindo-se de teorias e leis para a análise e explicação de fenômenos particulares (geral para o particular), utilizando-se de fontes secundárias e primárias e a técnica da pesquisa bibliográfica.

A situação-problema colocada em destaque no presente artigo é a garantia do emprego em condições de crise, mostrando se a mudança nas normas jurídicas laborativas é a solução ou não para manutenção do trabalhador em seu posto de trabalho.

Com o alto índice de desemprego provocado pela condição econômica do Brasil, eis que surge questionamentos sobre a flexibilização ou até mesmo a desregulamentação do Direito do Trabalho, com vistas a uma redução do custo de produção, melhorando a competitividade, e como uma saída para os empregadores que ainda mantêm suas empresas ativas. Por outro lado, não seria a Reforma das normas jurídicas laborais uma maneira oculta de destruição dos direitos fundamentais do trabalho?

Assim, consoante aos ditames de convívio numa sociedade equilibrada, com valores precípuos à dignidade humana, deve-se concluir que o ajuste da legislação trabalhista às tendências de um país em crise, deve compreender a adoção de medidas que harmonizem os interesses empresariais com a real medida de proteção aos que nele necessitam trabalhar.

\section{CRISE ECONÔMICA, GLOBALIZAÇÃO E O TRABALHADOR}

Crise econômica é uma fase de recessão caracterizada por ausência de investimentos, redução da produção, aumento do desemprego, um termo que tem sentido geral de situações desfavoráveis com frequência vinculadas à economia. Qualquer evento adverso, em especial os atinentes ao setor econômico, é "culpa da crise".

A palavra crise substituiu outras palavras que foram historicamente desvirtuadas, como "conjuntura" ou "depressão". Hoje prefere-se falar de "crise", em vez de "conjuntura" ou "depressão". Trata-se certamente de um termo mais neutro, que tem sido empregado em 
muitos outros contextos, além do econômico, sendo, assim muito familiar. O termo "crise" instiga menos medo.

[...] "crise", em seu sentido próprio, expressa algo positivo, criativo e otimista, pois envolve mudança e pode ser um renascimento após uma ruptura. [...] Há pouco tempo, a noção de "crise" se vinculou essencialmente ao setor econômico para indicar uma condição complexa e contraditória, que não pode ser definida como "inflação", "estagnação", "nem recessão", mas na qual uma série de causas se combinam numa mixórdia de questões conflitantes (BAUMAN, 2016, p. 11).

A atual crise do Brasil é principalmente financeira, e em consequência disso, percebese que empresas privadas não têm interesse em investir capital em países que estejam passando por sérias dificuldades, em parte em razão do arrocho no crédito bancário, mas principalmente em função de retornos econômicos inconsistentes, resultante da redução do consumo.

Com a crise econômica, ocorre curiosamente o aumento de preços dos bens essenciais, o que vai contra as tendências de mercado (eles deveriam cair em decorrência da diminuição da demanda): o aumento de valores procura compensar, a pequeno prazo, a redução das vendas, remunerando o produtor por prejuízos sofridos em razão da incapacidade de vender. Numa fase futura, se medidas corretivas adequadas não forem implementadas, a queda dos preços ao consumidor reduz a produção, gerando uma falta de bens essenciais e ocasionando novos aumentos forçados de preço, os quais buscam restaurar o equilíbrio entre oferta e procura.

Além disso, registra-se um aumento geral de preços dos bens de consumo (exemplo: o preço do feijão), juntamente com uma estagnação ou queda dos preços de mercado de bens imóveis. Esses são os mais óbvios dos sinais de uma séria escassez, a qual, se não corrigida, levará de maneira inevitável ao colapso econômico.

O aumento do preço dos bens de consumo não apenas desvia recursos do investimento e do mercado de bens imóveis, como também cria uma espécie de 'síndrome de Titanic', caracterizada por uma euforia contagiosa enquanto o país esta afundando (BAUMAN, 2016, p. 13).

Outro problema é a inflação. A inflação é uma das piores consequências de qualquer crise econômica visto que engole as economias de toda a vida e reduz as pessoas à fome num período muito pequeno: o dinheiro já não pode comprar mais coisa nenhuma, e instala-se o desespero. Um câncer altamente agressivo que se propaga no mesmo compasso da velocidade da moeda. Quanto mais rápido ela muda de mãos, menor valor tem. 
Ademais, existe também o desemprego. Em razão do encerramento de muitas empresas, houve uma grande queda no número de postos de trabalho, acarretando o desemprego, no qual o trabalhador brasileiro está demorando mais tempo para arranjar um novo emprego perante da crise econômica, sendo que o que mais assombra é a velocidade com que os índices de emprego pioram.

É um estado complicado para o empregado, pois gera problemas financeiros e, em muitos casos, problemas psicológicos, por exemplo: depressão, ansiedade, suicídio etc. Além disso, com a crise econômica muitas empresas ainda ativas estão demitindo seus empregados como forma de amortecer custos para enfrentar a crise.

Nessa linhagem, a flexibilização dos direitos trabalhistas foi apontada como uma das saídas do Estado para solução da crise econômica. Acredita-se que com a Reforma Trabalhista, seria possível minimizar o desemprego.

Outro elemento que vale a pena ressaltar é o processo de globalização e o avanço da tecnologia. Infelizmente, o fenômeno da globalização e os seus nefastos efeitos nas relações de trabalho é um problema que atinge, indistintamente, o trabalhador. "Globalização pode não ser uma palavra particularmente atraente ou elegante. Mas absolutamente ninguém que queira compreender nossas perspectivas no final do século pode ignora-la" (GIDDENS, 2007).

\begin{abstract}
Dentre as consequências sociais negativas da globalização é possível elencar: mudança da estrutura do mercado de trabalho, ocorrência do desemprego estrutural, criação de novas formas de relacionamento entre capital e o trabalho, fragmentação do movimento operário, rebaixamento dos trabalhadores na escala profissional, heterogeneização das relações salariais, aumento do fosso dentre os ganhos das várias categorias de operários, condenação ao desemprego crônico aos menos qualificados, vinculação da remuneração de várias relações salariais exclusivamente à produtividade, aumento da jornada de trabalho, encurtamento dos períodos de contratação, expansão do trabalho subcontratado e subsequente redução dos benefícios sociais, segmentação do mercado de trabalho (como a realocação das unidades produtoras e flexibilização das condições de recrutamento), adoção de contratos por tarefa, tendência ao uso de mão-de-obra cada vez mais qualificada e menos onerada com custos sociais, ocorrência do jobless growth (crescimento sem aumento correspondente da criação de novos postos de trabalho), redistribuição geoespacial da produção industrial, trabalhadores menos qualificados tendem a ser marginalizados do sistema produtivo da economia formal (diante do novo paradigma tecnológico-industrial), seleção biológica do trabalhador (sobrevivência apenas dos mais qualificados para exercerem múltiplas tarefas) (ZANOTI, 2006, p. 151-152).
\end{abstract}

O progresso da globalização, como processo de desenvolvimento do capitalismo mundial, quebra barreiras alfandegárias, rompe limites territoriais entre Estados, agiliza o trânsito de pessoas, de serviços, de capitais, de bens, e instaura um novo tempo econômico. Distingue-se pela nova lógica da mundialização da economia, pela incontida globalização de um capitalismo contemporâneo, e que demanda maior flexibilização das relações de trabalho, 
como maneira de manter-se competitivo perante um quadro de marcante concorrência, evento este que gera profunda decepção no âmbito social, e declínio no âmbito de proteção aos direitos trabalhistas.

Com a globalização e a crise econômica é admissível que as empresas procurem a redução de seus custos e o aperfeiçoamento tecnológico de sua produção, entretanto, é inaceitável que esses progressos aconteçam em prejuízo da preservação da dignidade da pessoa humana.

A Constituição da República de 1988 coloca o trabalho como um dos fundamentos do Estado Democrático de Direito Brasileiro ao lado da Dignidade da Pessoa Humana. Assim, o trabalho é visto como aquilo que dá à pessoa a oportunidade de inclusão social, o que eleva sua estima perante a sociedade e traz dignidade à sua vida. A Constituição Federal, deste modo, consolidou a importância do trabalho, solidificando inúmeros direitos dos trabalhadores.

A dignidade da pessoa humana é o princípio de maior importância axiológica na ordem jurídica contemporânea nacional e internacional, devendo nortear a interpretação e aplicação das normas, em especial no âmbito do Direito do Trabalho. Somente com a valorização do ser humano, enquanto ser que sobrevive, trabalha e interage com outros e com o respeito de suas diferenças pelo Direito, pela Sociedade e pelo próprio Estado, será possível apreender a dignidade do trabalhador (GAMBA, 2010, p. 32).

Contudo, diante o atual período econômico, o Estado busca novas alternativas para se posicionar perante as relações entre trabalhadores e empregadores, optando por uma filosofia mais liberal e menos intervencionista, admitindo que as relações de trabalho retrocedam a ser convencionadas pelo mercado, ignorando por completo as decorrências nefastas que tal política causou no Século XIX.

Dessa forma, uma das propostas que se apresentou como saída à crise do desemprego, entre outros problemas nascidos em resultado do processo de globalização, do avanço tecnológico e da economia de mercado foi a flexibilização das normas trabalhistas. Eis que surge novos questionamentos sobre flexibilização ou até mesmo a desregulamentação do Direito do Trabalho, com vistas a uma diminuição do custo de produção e melhorando da competitividade.

Não se deve confundir a desregulamentação com a flexibilização, pois enquanto aquela retira a proteção do Estado, permitindo a total autonomia privada, esta pressupõe a intervenção do Estado atuando de forma branda, assegurando as normas básicas, sem as quais não se pode conceber a vida do empregado com dignidade. (ORTEGA, 2015, p. 79). 
Porém, a flexibilização das normas laborais, deve ser considerada com cuidado, eis que não poderá colocar em risco os direitos adquiridos pelos trabalhadores, não podendo ser usada como mais um mecanismo de desculpa de empresários para abatimento das garantias trabalhistas.

Deve-se ter em mente que não se pode fazer desse momento, um momento para fazer mudanças na legislação que precarizem ou fragilizem as relações de trabalho. É admissível, pelo bom senso, de que na crise se adote medidas emergenciais. O que não se pode fazer é que as medidas emergenciais virem o modelo das regras trabalhistas daqui para frente.

\section{FLEXIBILIZAÇÃO TRABALHISTA}

A flexibilização trabalhista é, sem dúvida, um dos temas mais discutidos do Direito do Trabalho. Lidar com uma balança que incide, de um lado, os direitos dos trabalhadores e, de outro, os ganhos do empregador, é uma atividade muito complicada e conflituosa.

O Direito do Trabalho por meio de suas medidas protecionistas ou tutelares desempenha enorme papel na vida de todos os seres humanos, uma vez que o texto da Constituição estabelece no seu artigo $1^{\circ}$, inciso IV e no artigo 170, "caput", como pressuposto essencial, a dignidade da pessoa humana e a valoração do trabalho, que tanto está sendo ameaçada com o processo de globalização, crise econômica e com a Reforma Trabalhista que deseja a intervenção mínima do Estado nas relações de trabalho, visando apenas o interesse individual de empregadores que ambicionam maiores lucros, na disputa acirrada de mercado competitivo.

Pode-se notar sob o prisma da Constituição de 1988, o destaque dado ao trabalho, sobre tudo pertinente não só com o princípio da dignidade da pessoa humana, mas também da justiça social e valor social do trabalho.

Quando o texto constitucional entabula o valor da pessoa humana como um princípio fundamental no artigo $1^{\circ}$, inciso III, este deve ser concretizado sob diferenciados aspectos no contexto societário, seja no tocante ao próprio interesse individual da pessoa, seja no plano econômico ou social.

Nesse sentido, o que o que significa flexibilizar? Flexibilizar vem do latim flecto, flectis, flectere, flexi,flectum, que possuem o sentido de curvar, dobrar, fletir 
(MARTINS, 2009, p. 9). Mascaro define a flexibilização do Direito do Trabalho da seguinte forma:

\begin{abstract}
Flexibilização do direito do trabalho é a corrente de pensamento segundo a qual necessidades de natureza econômica justificam a postergação dos direitos dos trabalhadores, como a estabilidade no emprego, as limitações de jornada diária de trabalho, substituídas por um modulo anual de totalização da duração do trabalho, a imposição pelo empregador das formas de contratação do trabalho moldadas de acordo com o interesse unilateral da empresa, o afastamento sistemático do direito adquirido pelo trabalhador e que ficaria ineficaz sempre que a produção exigisse, enfim, o crescimento do direito potestativo do empregador, que romperia definitivamente com a relação de poder entre os sujeitos do vinculo de emprego, pendendo a balança para o economicamente forte (NASCIMENTO, 2003, p. 130).
\end{abstract}

O processo de flexibilização das normas trabalhistas em meio de crise econômica diante da globalização e desemprego como não poderia ser diferente, reflete no trabalhador. A flexibilização corresponde a "adequação" da legislação trabalhista com escopo social e econômico, admitindo que empresas se adaptem na produção, no emprego e nas condições de trabalho.

Parte da doutrina entende que a flexibilização das normas trabalhistas tem como alvo lutar contra o desemprego, o que será visto no próximo tópico, consequentemente amortizando ou eliminando custos de produção, o que pode ser harmonicamente favorável se respeitar os direitos trabalhistas que garantem a dignidade da pessoa humana.

O tema em evidência já estava sendo tratado, e depois de muitos protestos da oposição, a Reforma Trabalhista, Lei 13.467, de 13/07/2017, foi publicada no Diário Oficial da União em 14 de julho de 2017 com "vacatio legis" de 120 dias, entrando em vigor em 11 de novembro de 2017.

Esse tema já era antigo e criticado por muito doutrinadores, pois flexibilizar contratos trabalhistas como maneira exclusiva e inafastável de propiciar um aumento na geração de empregos, na ânsia de luta ao crescente desemprego, com vistas ao desenvolvimento econômico e social, pode originar sérios riscos aos empregados, pois tirando do Estado o poder intervencionista, retiraria o manto protetor que defende os trabalhadores, fato este que poderia levar a consequências catastróficas não apenas para a saúde do trabalhador, mas também aumentaria os acidentes de trabalho, doenças psíquicas, afetaria a família, e, por conseguinte estaria matando o princípio da dignidade da pessoa humana, e não mais seria nomeado como flexibilização, mas sim como flexploração (GROSSO, 2007, p. 52-53).

Conforme Dinaura Godinho Pimentel Gomes: 
consequentemente, em detrimento desses mesmos princípios e regras que resguardam aquele mínimo de dignidade, duramente conquistado (GOMES, 2005, p. 92).

E vai mais além ao afirmar que:

Na verdade, tais imposições advindas do neoliberalismo e da globalização, trazem pois, como resultado, o amargo retorno à pré-modernidade, o que evidencia a volta da barbárie; ou, mais precisamente impõe uma nova forma de regulação feudal, a ignorar completamente o longo percurso da conquista desses direitos (GOMES, 2005, p. 93).

De tal modo, a Reforma Trabalhista já aprovada poderá redundar na descaracterização do próprio Direito do Trabalho, a partir do momento que o mesmo é abrangido como instrumental imprescindível à proteção do trabalho humano.

Por outro lado, a quem defenda que a aprovação da referida Reforma que altera a Carta Trabalhista, propõe a possibilidade da flexibilização das normas laborais, observando sempre o respeito e as conquistas pelo advento da Constituição Federal de 1988, mas possibilitando, em caso de comprovação da dificuldade econômica, a flexibilização. Dessa forma a flexibilização seria a capacidade de renúncia a determinados costumes e de adaptação a novas situações.

Denominações como "direito do trabalho da crise", "da emergência", são termos usados dando a ideia da necessidade de adoção de novas medidas em face da crise econômica. De fato, a relativização das normas trabalhistas possui intensa ligação com tempos de crise, porém não se sintetiza exclusivamente a tais períodos, buscando a maior dinâmica das relações laborativas em todo tempo.

Assim, a Reforma das normas laborais foi apontada como meio de solução rápida em meio a crises econômicas, consoante à atenuação do impacto negativo nas empresas, de forma a operar em prol da manutenção e oferta de emprego.

As crises econômicas, pelo seu caráter de excepcionalidade, demandam medidas urgentes do Estado, de maneira a conter o impacto econômico nos âmbitos produtivos. A maior abertura das normas trabalhistas seria uma forma dinâmica de adaptação das empresas frente a um novo quadro econômico, de maneira a impedir problemas maiores à economia interna, e concomitantemente, garantir a manutenção do emprego.

\section{REFORMA DOS DIREITOS TRABALHISTAS: GERAÇÃO E MANUTENÇÃO DE EMPREGOS?}


As principais causas de falta de emprego no Brasil são de ordem econômica (perda de renda), psicológica (perda de autorrespeito) e social (aumento da violência, corrupção e crimes). Além dessas, outros fatores podem ser elencados como causadores do desemprego: rigidez do mercado de trabalho (salário mínimo, legislação de seguridade, custos laborais, fraco poder sindical); desenvolvimento econômico; globalização; crises econômicas; encargos sociais; diminuição do crescimento econômico e insuficiência da demanda global; evolução da tecnologia; redução da qualificação do trabalhador e aumento da competitividade internacional.

\begin{abstract}
No Brasil, são evidentes as causas conjunturais e estruturais do desemprego. Conjunturalmente podem ser identificados os elevados encargos sociais, as diferenças cambiais, as altas taxas de juros e a falta de investimento. As causas estruturais são: globalização da economia com todos os seus efeitos sobre a competitividade dos mercados, inclusive a dos produtos importados entrados, regularmente ou não no mercado interno de consumo; falência do Estado que não conseguiu reduzir, sua imensa e, geralmente, ineficaz máquina; rigidez da legislação trabalhista e obsolescência do Direito, com excesso de normas de pouco eficácia e recente utilização de novas técnicas, incluindo a automação e a informatização (FRANCO FILHO, 1998, p. 127).
\end{abstract}

Nasce então o discurso da Reforma das normas Trabalhistas, arraigando-se por assim dizer o ponto central da defesa neoliberal, que é um primeiro momento a flexibilização e num segundo a desregulamentação, enquanto formas de atender as necessidades novas surgidas, como por exemplo, uma simplificação nos processos de contratação e demissão do empregado. São elementos tidos como necessários para a geração de emprego e atendimento das novas necessidades surgidas no novo mundo do trabalho. Também, a não interferência do Estado nas relações de trabalho, extinguindo-se em parte as regras protetivas do trabalhador.

Antes da entrada em vigor da Lei 13.467, de 13/07/2017, a CLT, Decreto-Lei $n^{\circ} 5.452$, de 1 de maio de 1943, sancionada pelo então presidente Getúlio Vargas, baseada no protecionismo do empregado em sentido clássico, já estava em crise.

Dentre os fatores que desencadearam a crise merecem ênfase: as transformações do mercado de trabalho e do sistema produtivo provocadas pela globalização. Nesse panorama, o universo dos trabalhadores que demandam proteção jurídica é cada vez mais largo, não podendo o Direito do Trabalho ignorar a existência do trabalho autônomo, dos contratos atípicos flexíveis e de outras formas de labor diversas da relação de emprego (ORTEGA, 2015, p. 80).

A Reforma Trabalhista foi utilizada então como forma de contenção de crise econômica, buscando-se impedir a despedida em massa de um grande número de empregados. Tal mudança promete afrouxar, eliminar ou adaptar, de acordo com os casos concretos, a 
proteção trabalhista clássica, para aumentar o emprego, a inversão ou a competitividade internacional.

Analisa-se pelas colocações doutrinárias dos defensores da reforma que a excessiva rigidez das normas trabalhistas, ao invés de desempenhar a proteção da forma intentada ao empregado, acaba por provocar a diminuição da oferta do emprego e menor permanência do vínculo empregatício, de maneira a motivar, ao menos em parte, efeito inverso ao pretendido.

Sérgio Pinto Martins defendia até então que o aumento do desemprego também era causado, entre outras hipóteses, pela rigidez da legislação trabalhista. Daí se almejar flexibilizar a relação de trabalho para a diminuição do desemprego, a eliminação de horas extras, o trabalho a tempo parcial, a divisão do posto de trabalho, etc (MARTINS, 2009, p. 36).

Para Luiz Carlos Amorim Robortella, a flexibilização do contrato individual de trabalho seria o caminho apto para uma maior oferta de empregos. Por meio, da ampliação do bojo de tarefas (polivalência) do trabalhador, este estaria suscetível a ocupar os mais diversos postos de trabalho, o que lhe permitiria tanto a continuação na mesma empresa (remanejamento), como a procura por outro posto de trabalho, com maior facilidade (ROBORTELLA, 1994, p. 101).

Entretanto ao observar a garantia mínima de direitos dos trabalhadores, não seria a reforma das normas jurídicas laborais uma forma oculta de extinção dos direitos fundamentais trabalhistas?

A solução para o desemprego não esta na reforma das normas de trabalho, pois, o Estado brasileiro não é ressalva do fenômeno do desemprego, e como acredita a corrente flexibilista a solução não é a desregulamentação ou a flexibilização. A legislação não era rígida assim como aludiam os adeptos da flexibilização, pois, até mesmo a própria Constituição admitia determinadas formas de flexibilização no Direito do Trabalho.

A Reforma Trabalhista é prejudicial aos trabalhadores. Isso porque trata-se de prerrogativas que oferecem vantagens ao capital, mesmo porque, se assim não fosse, ao empregador de nada adiantaria e, portanto, dela não se utilizaria. E, se é forma de economizar com mão-de-obra, é evidente que resulta em prejuízo aos empregados. Não obstante isso, tal fenômeno é fruto dos tempos atuais, da grande concentração de capitais e das leis de mercado que se vive.

O Direito do Trabalho, tem por finalidade regulamentar as normas jurídicas que disciplinam as relações de trabalho, visando garantir, sempre, melhores condições de trabalho a parte mais fraca da relação laboral que é o empregado. Seu principal intento é assegurar 
melhores condições de trabalho, levando em apreço a dignidade do ser humano, enquanto o mesmo consegue por meio do trabalho, as suas realizações particulares.

Nesse sentido, faz-se necessário alguns comentários diante da entrada em vigor da Lei 13.467, de 13/07/2017, a qual alterou a CLT, a iniciar pelos princípios do Direito do Trabalho.

Antes da Reforma, o Princípio da Norma Mais Favorável, era aplicado quando houvesse mais de uma norma igualmente aplicável ao caso concreto, e assim escolheria sempre a mais favorável ao trabalhador, contudo a partir de 11 de novembro de 2017, o Princípio da Norma Mais Favorável foi mitigado, pois foi admitido negociação coletiva contrária a Lei e "in peius" (para pior) nas matérias previstas pelo art. 611-A, CLT, ou seja, passam a existir exceções, podendo o Sindicato negociar direitos para pior em todas as matérias que dispostas no art. 611-A.

A Reforma Trabalhista traz o Princípio do Negociado sobre o Legislado em 15 pontos, no art. 611-A, CLT, incluindo aí o pacto quanto a jornada de trabalho, o banco de horas anual, os intervalos intrajornadas e ainda traz que poderá prevalecer o negociado pelo legislado no tocante a prorrogação de jornada em ambientes insalubres, sem licença prévia das autoridades competentes do Ministério do Trabalho, rol esse não taxativo e sim explicativo.

\footnotetext{
Art. 611-A. A convenção coletiva e o acordo coletivo de trabalho têm prevalência sobre a lei quando, entre outros, dispuserem sobre:

I - pacto quanto à jornada de trabalho, observados os limites constitucionais;

II - banco de horas anual;

III - intervalo intrajornada, respeitado o limite mínimo de trinta minutos para jornadas superiores a seis horas;

IV - adesão ao Programa Seguro-Emprego (PSE), de que trata a Lei no 13.189, de 19 de novembro de 2015;

V - plano de cargos, salários e funções compatíveis com a condição pessoal do empregado, bem como identificação dos cargos que se enquadram como funções de confiança;

VI - regulamento empresarial;

VII - representante dos trabalhadores no local de trabalho;

VIII - teletrabalho, regime de sobreaviso, e trabalho intermitente;

IX - remuneração por produtividade, incluídas as gorjetas percebidas pelo empregado, e remuneração por desempenho individual;

$\mathrm{X}$ - modalidade de registro de jornada de trabalho;

$\mathrm{XI}$ - troca do dia de feriado;

XII - enquadramento do grau de insalubridade;

XIII - prorrogação de jornada em ambientes insalubres, sem licença prévia das autoridades competentes do Ministério do Trabalho;

XIV - prêmios de incentivo em bens ou serviços, eventualmente concedidos em programas de incentivo;

XV - participação nos lucros ou resultados da empresa.
} 
A Lei 13.467/2017 também alterou a redação do art. $4^{\circ}$, CLT, acrescentando os $\S \S 1^{\circ} \mathrm{e}$ $2^{\circ}$, retirando até então o tempo despendido pelo empregado à disposição do empregador, não sendo mais computado como período extraordinário o que exceder a jornada normal:

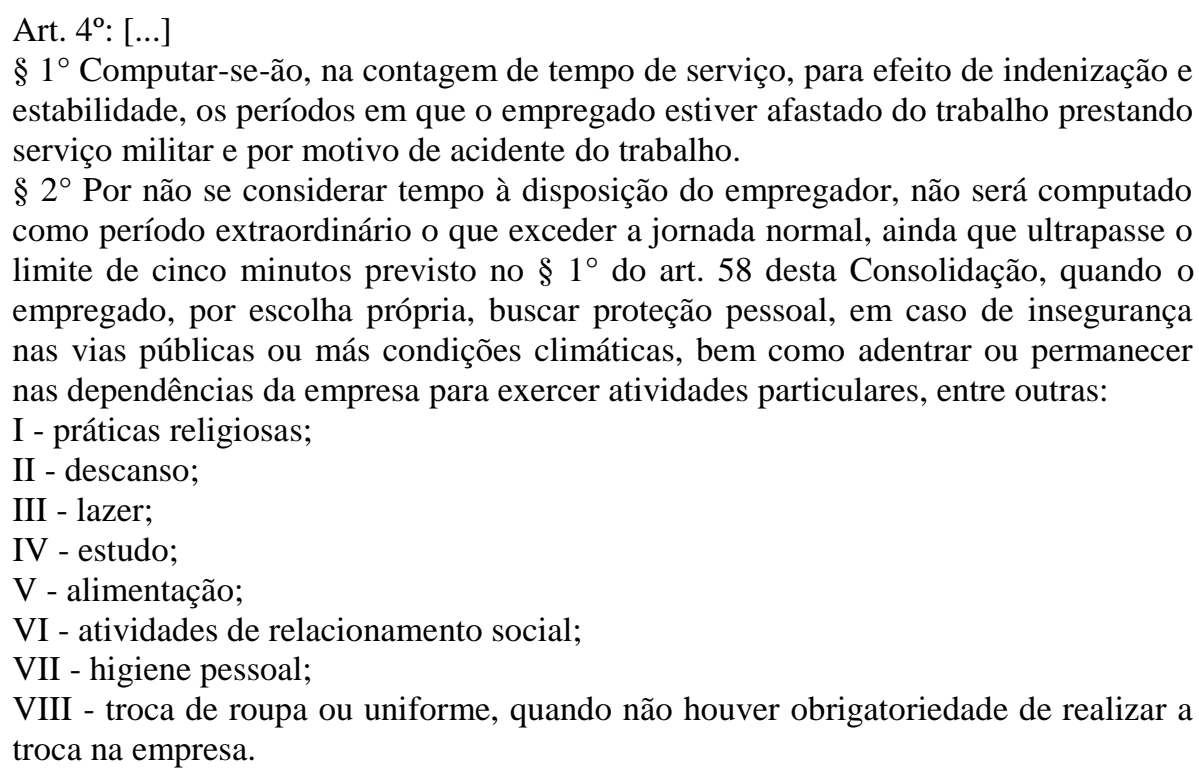

Outra alteração legislativa que merece destaque é a alteração do $\S 2^{\circ}$ da CLT e revogação do $\S 3^{\circ}$ do art. 58, CLT:

Art. 58: [...]

$\S 20$ O tempo despendido pelo empregado desde a sua residência até a efetiva ocupação do posto de trabalho e para o seu retorno, caminhando ou por qualquer meio de transporte, inclusive o fornecido pelo empregador, não será computado na jornada de trabalho, por não ser tempo à disposição do empregador.

Ou seja, a Reforma Trabalhista trouxe o fim das horas "in itineres" (inclusive revogando a Súmula 90, TST, por inteiro).

Na parte de Processo do Trabalho merece evidência a questão do Impulso Oficial, o antigo art. 878, CLT, previa que a execução poderia se iniciar e tramitar de ofício, como por exemplo, na desconsideração da pessoa jurídica não se exigia o requerimento da parte ou do MP.

Art. 878 - A execução poderá ser promovida por qualquer interessado, ou ex officio pelo próprio Juiz ou Presidente ou Tribunal competente, nos termos do artigo anterior.

Com a Reforma Trabalhista, se alterou o artigo citado para prever que o impulso oficial somente terá aplicação na hipótese da parte exercer o "ius postulandi”. 
Art. 878. A execução será promovida pelas partes, permitida a execução de ofício pelo juiz ou pelo Presidente do Tribunal apenas nos casos em que as partes não estiverem representadas por advogado.

Cumpre destacar que o presente tópico não tem a função de esgotar as mudanças provocas pela lei 13.467/2017, ao contrário busca apenas analisar se a Reforma Trabalhista gera empregos e mantém empregos de milhares de trabalhadores. Até porque tal tema ainda é bastante embrionário e seus reflexos só serão vistos com o passar dos anos.

Nesse sentido pode-se dizer que somente com essa pequena abordagem rápida da alteração desses artigos acima mencionados, houve uma precarização de direitos dos trabalhadores. Tais mudanças não levaram em conta a Constituição Federal de 1988, mais especificamente o artigo 170, "caput", e o artigo $1^{\circ}$, merecendo realce o princípio da dignidade da pessoa humana, o artigo $3^{\circ}$, e seus atinentes incisos que constituem em especial a garantia do desenvolvimento nacional bem como o artigo 193 também da Constituição Federal de 1988, que por sua vez, institui que a ordem social tem como base o primado do trabalho, e como objetivos o bem estar e a justiça social.

Nestes dispositivos constitucionais podem ser achados os limites da flexibilização, concluindo que a Reforma Trabalhista não levou em conta os parâmetros principiológicos constitucionais, representando ofensa ao Estado Democrático de Direito. Como se não bastasse estes argumentos, tem se ainda os princípios norteadores do Direito do Trabalho, funcionando como um vetor para o interprete indicando os horizontes a serem seguidos, e com a Reforma tais princípios serão mitigados.

O trabalho não tem sentido de meio de produção, é a base única que diz respeito à própria sobrevivência humana, ou seja, a Constituição Federal de 1988, ao salientar o valor do trabalho humano, repudia a sua degradação de mero objeto.

Ficou claro que a Reforma Trabalhista beneficia apenas o empregador hipersuficiente pois apresenta redução de custos ao empresário restringindo direitos e garantias conquistados a duras penas, pelos empregados.

Uma vez que os alvos da Reforma Trabalhista são voltados para a retirada e diminuição das intervenções do Estado nas relações de trabalho, clara sua limitação, por meio do princípio da dignidade da pessoa humana, que visa garantia a todo ser humano, contra abuso de direitos, até mesmo por parte do próprio Estado.

A dignidade da pessoa humana se proclama na noção de que o ser humano é sempre um valor em si e por si, e exige ser respeitado e tratado como tal, e jamais ser considerado e tratado como um peça que se usa, um instrumento, uma coisa e, mais tudo o que há sobre a 
terra deve ser ordenado em função do homem, como seu centro e seu termo. A dignidade humana está intrinsecamente ligada ao respeito à liberdade e à igualdade dos seres humanos (CARDOSO, Curitiba, 2003).

Desta forma, é certo dizer que não apenas o Estado, mas todos os seres humanos devem obediência e respeito ao princípio da dignidade da pessoa humana, especialmente no domínio do Direito do Trabalho, onde precisam ser reverenciados os direitos e garantias fundamentais dos trabalhadores.

De outro lado também esta a obrigação do Estado, por meio de políticas públicas, buscar soluções para o problema da crise econômica, sempre levando em consideração o princípio da dignidade da pessoa humana e a valorização do trabalho.

A Reforma Trabalhista destrói direitos e garantias fundamentais do trabalhador, ao ponto do trabalhador ter que abandonar direitos irrenunciáveis, bem como retirando a intervenção por parte do Estado consentindo a livre negociação realizada entre empregado e empregador, como se dois estivessem no mesmo nível de igualdade.

A alteração da CLT não era o caminho para a salvação da crise econômica do Brasil, podendo até ser agora um retrocesso para o desenvolvimento social, por ter objetivos voltados a destruir direitos e garantias fundamentais.

A simplificação dos tributos, melhores investimentos no setor produtivo, a redução dos gastos públicos, melhorar a competitividade e qualidade dos produtos e serviços, a capacidade de criar e adaptar produtos, o combate à corrupção, investimentos em inovação científica e tecnológica, dentre outros, são saídas para garantirem o aumento da participação no comércio global, fortificando a expansão do setor produtivo e o desenvolvimento da economia, e, por consequência, a possível solução do problema da crise econômica, sem a necessidade de se pôr em prática medidas flexibilizatórias, além das já permitidas até então.

Enfim, infelizmente com Reforma Trabalhista, houve uma drástica redução de direitos e desmantelamento do sistema de relações de trabalho, houve uma redução do papel do Estado em relação à proteção ao trabalhador, o que deve tornar pior as condições de vida e trabalho e a capacidade de negociação dos sindicatos em cenário econômico extremamente adverso. Assim, reverte, de forma cabal, os fundamentos legais, políticos e ideológicos que nortearam, até agora, as relações entre Estado, capital e trabalho no Brasil.

\section{CONSIDERAÇÕES FINAIS}


Este trabalho teve como meta discutir a Reforma das normas trabalhistas como forma de atingir a crise econômica e consequentemente gerar, manter empregos e diminuir o desemprego no Brasil. Tal pesquisa teve como alvo apresentar uma visão geral sobre o tema, visto que o processo de flexibilização dos direitos laborais, ainda que guarde suas polêmicas, é assunto em evidência na realidade econômica do Brasil.

O tema é convidativo, e não se esgota nas páginas deste artigo. Compreender os impactos que podem gerar a alteração da CLT, sem dúvida não é tarefa fácil, mas ficou evidenciado que beneficiará maiormente as empresas. Por outro lado, pode-se também destruir direitos e garantias fundamentais do trabalhador, pois retira a intervenção por parte do Estado consentindo a livre negociação realizada entre empregado e empregador.

Enfim, a aplicabilidade da manutenção de direitos laborais precisa sempre observar a garantia constitucional da dignidade humana que está conectada a proteção do empregado. Deste modo, está aí causa mais do que suficiente para que o trabalho seja valorizado, porque eivado de interesse social, pois está em jogo a dignidade da pessoa humana, uma vez que incide (o trabalho) na fonte de sobrevivência material do trabalhador.

A possibilidade de manutenção dos direitos laborais é um tema que merece ser estudado com maior profundidade e responsabilidade, devendo tanto sindicatos, empresários, e até mesmo o Estado encontrar um equilíbrio para a crise financeira de modo que não afete o empregado. Com isso, a Reforma Trabalhista, mesmo que embrionária, parece não ser a melhor solução para crise econômica do Brasil, podendo até ser um retrocesso para o desenvolvimento social, destruindo direitos e garantias fundamentais.

\section{REFERENCIAS}

BAUMAN, Zygmunt; BORDONI, Carlo. Crise do Estado. Título original: State of crisis. Tradução: Renato Aguiar. 1. ed. Rio de Janeiro. Zahar, 2016.

BRASIL. Consolidação das Leis do Trabalho. Disponível em: <http://www.planalto.gov.br/ccivil_03/Decreto-Lei/Del5452.htm>. Acesso em 14 out. 2017.

Constituição da República Federativa do Brasil de 1988. Disponível em:

<http://www.planalto.gov.br/ccivil_03/Constituicao/Constituicao.htm>. Acesso em 14 out. 2017. 

out. 2017.

CARDOSO, Luciane. Direitos humanos e trabalhadores: atividade normativa da Organização Internacional do Trabalho e os limites do Direito Internacional do Trabalho. Curitiba, 2003. 332 f. Tese (Doutorado) - Universidade Federal do Paraná.

DAL ROSSO, Sadi. A Jornada de trabalho na sociedade: o castigo de Prometeu. São Paulo: LTr, 1996.

FRANCO FILHO, Geogenor de Souza. Desemprego: mudanças nas relações de trabalho. 1 ed. São Paulo: LTr, 1998.

GAMBA, Juliane Caravieri Martins. Dignidade do Trabalhador e Políticas Públicas: Perspectivas no Âmbito do Estado Ético. In PIOVERSAN, Flávia; CARVALHO, Luciana Paula Vaz de. (Coord). Diretos humanos e direito do Trabalho. São Paulo: Atlas, 2010.

GIDDENS, Anthony. Mundo em descontrole o que a globalização está fazendo de nós. Tradução de Maria Luiza C. de A. Borges. 6ª ed. Rio de Janeiro: Record, 2007.

GOMES, Dinaura Godinho Pimentel. Direito do Trabalho e Dignidade da Pessoa Humana, no Contexto da Globalização Econômica Problemas e Perspectivas. São Paulo: LTr, 2005.

GROSSO, Cristiano Pinheiro. Limites da flexibilização no Direito do Trabalho à luz do desenvolvimento econômico e social. Dissertação (Mestrado em Direito) - UNIMAR, Marília - SP, 2007.

MARTINS, Sérgio Pinto. Flexibilização das condições de trabalho. 4. Ed. - São Paulo : Atlas, 2009.

NASCIMENTO, Amauri Mascaro. Curso de Direito do Trabalho. São Paulo: Saraiva, 2003.

ORTEGA, Luitt Conceição. O Contemporâneo Direito do Trabalho no Brasil e as práticas flexibilizatórias. Dissertação (Mestrado em Direito) - UNIMAR, Marília - SP, 2015.

ROBORTELLA, Luiz Carlos Amorim. O moderno direito do trabalho. São Paulo: LTr, 1994. 
ZANOTI, Luiz Antônio Ramalho. A função social da empresa como forma de valorização da dignidade da pessoa humana. Dissertação (Mestrado em Direito) - UNIMAR, Marília - SP, 2006.

\title{
THE REFORM OF THE LABOR STANDARDS IN THE MEANING OF THE ECONOMIC CRISIS IN BRAZIL
}

\begin{abstract}
The present work contemplates an analysis of the labor rights reform, to provide subsidies to the construction of solutions to the current economic crisis experienced by Brazil. In this sense, it has as its main question whether alteration of labor rights acts for the generation and maintenance of jobs. It has as specific objectives: to evaluate the benefits and impacts that the maintenance of labor rights can cause; define crisis; to exemplify the harms caused by globalization to the worker, to address the issue of unemployment and the interference of the State in relation to the process of flexibilization. The work is a bibliographical one, having as deductive method, based on the consultation of primary and secondary sources. Finally, the work seeks to reach answers, so that the unemployment rate decreases, showing if the change in labor legal norms is or is not the solution to the maintenance of the worker at his job and an exit to economic crisis.
\end{abstract}

Keywords: Unemployment. Economy. Legal regulation of work. 